\title{
O USO DOS VEÍCULOS NÃO TRIPULADOS NO MONITORAMENTO
} AMBIENTAL NA AMAZÔNIA

\section{THE USE OF THE UNMANNED VEHICLES IN ENVIRONMENTAL MONITORING IN THE AMAZON}

\author{
${ }^{1}$ Juliana Carvalho Fontes \\ ${ }^{2}$ Valmir César Pozzetti
}

\section{RESUMO}

O objetivo deste trabalho é analisar a legislação sobre Drones no ordenamento jurídico brasileiro e verificar se sua aplicabilidade na proteção ambiental é eficaz. Conclui-se que a aplicabilidade dessa novel tecnologia é saudável, vez que esse equipamento possibilita realizar atividade de sustentabilidade que o ser humano não consegue realizar com a mesma eficiência. Dessa forma, a utilização desse equipamento em defesa do meio ambiente e na fiscalização e monitoramento das reserva da Amazônia se mostra viável. A Metodologia utilizada nesta pesquisa é a do método dedutivo e quantos aos meios e fins, a pesquisa é a bibliográfica e qualitativa.

Palavras-Chave: Monitoramento ambiental. Drones. Sustentabilidade; Amazônia; Meio ambiente.

\section{SUMMARY}

The aim of this study is to analyze the legislation on Drones in the Brazilian legal system and verify its applicability in environmental protection is effective. It is concluded that the applicability of this novel technology is healthy, since this equipment allows carrying out sustainability activity that a human being cannot perform with the same efficiency. In this way, the use of this equipment in environmental protection and in the supervision and monitoring of the Amazon appears feasible. The methodology used in this research is the deductive method and the means and ends, the search is the bibliographical and qualitative.

Keywords: environmental monitoring. Drones. Sustainability; Amazon; Environment.

\footnotetext{
${ }^{1}$ Mestranda em Direito Ambiental pela Universidade do Estado do Amazonas - UEA, Amazonas (Brasil).

${ }^{2}$ Doutor em Direito Ambiental pela Université de Limoges - UNILIM (França). Professor pela Universidade do Estado do Amazonas - UEA, Amazonas (Brasil). E-mail: v_pozzetti@hotmail.com
} 


\section{INTRODUÇÃO}

O meio ambiente natural brasileiro possui uma diversidade enorme, seja no tocante à fauna, flora, lacustre, etc... Algumas regiões, de floresta ou aquática, são inóspitas, dificultando o acesso humano.

Neste sentido, as espécies em extinção precisam de acompanhamento e monitoramento mais próximo, o que é por vezes difícil, dado o local onde se encontram ou vivem.

Dessa forma, a problemática que se coloca nessa pesquisa é : de que forma os VANTs - Veículos Não Tripulados - poderão auxiliar nas atividades relacionadas à proteção ambiental ?

O estudo se justifica em razão de que outros países estão desenvolvendo esta tecnologia, com resultados positivos no âmbito da preservação ambiental/ sustentabilidade. Como é uma tecnologia nova, há criticas sobre os efeitos negativos que ela poderia causar ao meio ambiente.

Entretanto, o emprego de Vant's para a conservação da biodiversidade já é reconhecido como uma estratégia bastante eficaz em alguns continentes, como África e Ásia.

Na Austrália, um experimento de monitoramento do Dugongo - um tipo de mamífero aquático semelhante ao peixe-boi - foi feito com Vant's e trouxe resultados mais rápidos, mais baratos e mais refinados do que o método tradicionalmente utilizado de enviar um grupo de pesquisadores a bordo de um avião.

A aplicação da tecnologia no cenário brasileiro ainda é tímida ou realizada de forma isolada. Neste sentido, o objetivo desta pesquisa é analisar a legislação existente e verificar se ela permite o uso destes equipamentos e quais as consequências do uso destes. Uma vez que a lei que regulamenta seu uso não traz regras claras para este tipo de finalidade.

A iminente regulamentação do uso profissional dos Drones e os altos investimentos para o desenvolvimento e uso dessa tecnologia em diferentes áreas da economia dão uma perspectiva de crescimento muito grande para esse mercado.

A metodologia utilizada nesta pesquisa é a do método dedutivo; quantos aos meios a pesquisa é bibliográfica - com consulta à doutrina, legislação e arquivos eletrônicos - e quanto aos fins, a pesquisa é qualitativa. 


\section{REGULAMENTAÇÃO DOS DRONES NO BRASIL}

Ao falarmos sobre a regulamentação de drones, é preciso dizer que a introdução desta tecnologia tem amparo no principio de direito ambiental convalidado na convenção internacional de direito Ambiental, a chamada Rio/92 ou ECO/92 : o Princípio do Desenvolvimento Sustentável.

No caso dos drones, verifica-se que os benefícios que ele pode trazer, no tocante à fiscalização, controle e monitoramento ambiental, são muitos.

Segundo Machado (2.015, p. 32), o "Princípio do Desenvolvimento Sustentável é o Mega dos "megas" princípios da Declaração do Rio, a ECO/Rio/92". Esse principio foi criado na Conferência de Estocolmo/Suécia/1972 e está consignado na convenção Internacional do Rio de Janeiro de 1.992:

Princípio 4. A fim alcançar o desenvolvimento sustentável, a proteção do ambiente deverá constituir-se como parte integrante do processo de desenvolvimento e não poderá ser considerada de forma isolada. (gn)

Dessa forma, sendo o Drone um aeromodelo de controle remoto, sem piloto embarcado e manipulado por controle remoto, à distância, com diversos usos que vão desde o lazer até o uso militar, verifica-se que essa tecnologia poderá ser bastante útil; senão vejamos: os drones militares possuem tecnologia distinta e, como cérebro, possuem um microcontrolador com processador e memoria com software; são utilizados para voos no interior de prédios e construções fechadas, para verificar a normalidade ou anormalidade.

No Brasil, a Instrução Suplementar - IS No 21-002a , da Agência Nacional de Aviação Civil (Anac), publicada em outubro de 2012, define VANT como :

\footnotetext{
Aeronave projetada para operar sem piloto a bordo, que possua uma carga útil embarcada e que não seja utilizado para fins meramente recreativos. Nesta definição incluem-se todos os aviões, helicópteros e dirigíveis controláveis nos três eixos, excluindo-se, portanto, os balões tradicionais e aeromodelos.
}

A Portaria n. 415 DGCEA de 09/11/2015 aprovou a regulamentação do Sistema de aeronoves Remotamente Pilotadas e o acesso ao espaço aéreo brasileiro, em conformidade com o previsto no Decreto n. 6.834 de 30/04/2009. Em seu subitem n. 2.1.4 a Portaria n.415/2015 define RPA - Aeronave Remotamente Pilotada como "aeronave não tripulada, pilotada a partir de uma estação de pilotagem remota". 
Não há legislação específica que restrinja a compra de drones no Brasil. Assim, qualquer cidadão pode comprar um drone, de qualquer tamanho e potência, e o produto é geralmente disponibilizado em sites nacionais e internacionais ou comercializado por lojas físicas e empresas fabricantes.

Por outro lado, o Brasil regulamenta o uso que se faz dos equipamentos. Drones adquiridos para aeromodelismo não podem ser usados em áreas densamente povoadas; não podem ser pilotados em áreas próximas a aeródromos; a altitude máxima permitida é de 121,92 metros e só pode haver público se o usuário for experiente e houver segurança durante o voo, para evitar qualquer acidente.

Porém, não há necessidade de licença para se utilizar o drone de forma recreativa, desde que as regras supracitadas sejam obedecidas. Essas diretrizes estão expostas na Portaria DAC N 207 , de 07 de abril de 1999, e estabelece as regras para a operação do aeromodelismo no Brasil.

No caso dos VANT's, o uso é permitido apenas com piloto remoto. Isso quer dizer que equipamentos autônomos, sem intervenção externa durante o voo, são proibidos pela defesa aérea brasileira. Logo, todo VANT que possui um piloto remoto é automaticamente chamado de remotely-piloted aircraft (RPA), em português, aeronave remotamente pilotada (ARP), sigla adotada pela Força Aérea Brasileira.

Os RPAs são regulados por uma Circular de Informações Aeronáutica (AIC 21/10) que determina que o interessado encaminhe uma solicitação de autorização de voo 15 dias antes com uma série de informações (características da aeronave, trajeto do voo, capacidade de comunicação etc).

Quando os VANTs são utilizados para fins de pesquisa, como no caso de universidades que utilizam o equipamento para fazer algum tipo mapeamento de relevo, tipos vegetais, pesquisa das condições atmosféricas, entre outros, existe uma autorização própria chamada de Certificado de Autorização de Voo Experimental (CAVE).

Para qualquer um dos casos, além da autorização de uso do equipamento junto à Anac, os pilotos precisam pedir liberação de voo aos órgãos regionais do Decea (Cindacta I, Cindacta II, Cindacta III, Cindacta IV, SRPV-SP), assim como é feito no caso de aeronaves tripuladas. 


\section{O USO DOS DRONES E A PROTEÇÃO AO MEIO AMBIENTE}

As questões ambientais que assolam o planeta estão se intensificando cada vez mais, pelo uso indiscriminado dos bens primários, uso desenfreada da produção de bens de consumo.

Com isso, restringe-se os espaços, promove-se queimadas para o plantio de áreas novas, derruba-se a mata para a utilização de madeira e transformação da floresta em pastos para bovinos, causando prejuízos ao meio ambiente e aos povos que habitam o planeta terra.

A crise ambiental vem se intensificando a cada ano, muito embora os dirigentes do orbe tenham intensificado ações para remodelar o modo de vida dos humanos.

Mas as ações humanas tem provocado inúmeros desequilíbrios que necdessitam ser cessados ou diminuídos; pois a "mãe terra" não conseguirá manter a vida no planeta por muito tempo caso o consumo continue acelerado.

Nesse sentido a Constituição Federal estabelece :

\footnotetext{
Art. 225. Todos têm direito ao meio ambiente ecologicamente equilibrado, bem de uso comum do povo e essencial à sadia qualidade de vida, impondo-se ao Poder Público e à coletividade o dever de defendê-lo e preservá- lo para as presentes e futuras gerações.

$\S 1^{\circ}$ Para assegurar a efetividade desse direito, incumbe ao Poder Público: I - preservar e restaurar os processos ecológicos essenciais e prover o manejo ecológico das espécies e ecossistemas;

II - preservar a diversidade e a integridade do patrimônio genético do País e fiscalizar as entidades dedicadas à pesquisa e manipulação de material genético; (gn)
}

Vê-se, portanto, que a legislação maior estabelece que é obrigação do Poder Público e da coletividade defender e preservar o meio ambiente. Assim, todas as ações que visem estimular e garantir o uso sustentável e a preservação do meio ambiente, estão amparados pelo texto legal.

Assim, o uso de drones, para monitorar e auxiliar nos processos de sustentabilidade tem fundamento no artigo 225 da Constituição Federal.

Como resposta a esses desafios, veículos aéreos não tripulados (VANT's), popularmente chamados drones, estão se consolidando como a mais nova tendência em sensoriamento remoto.

Além do menor custo de aquisição de dados quando comparados às plataformas tradicionais, as aeronaves não tripuladas trazem a possibilidade de monitoramento de atividades ilícitas em tempo real, o que torna esse instrumento uma excelente alternativa para a área de segurança e abre novas perspectivas para o monitoramento de ilícitos ambientais. 
Importante destacar que, no Brasil, os drones são classificados e regulados conforme sua aplicação. Se for para lazer, esporte, hobby ou competição, o equipamento é visto como um aeromodelo. Se o uso do drone for para outros fins (pesquisa, experimentos ou comércio), o aparelho passa a ser classificado como um veículo aéreo não tripulado (VANT).

Essa nomenclatura em português correspondente à terminologia em inglês UAV unmanned aerial vehicle - adotada pelo Departamento de Defesa Norte Americano.

Não faz muito tempo, os drones (veículo aéreo não tripulado, ou simplesmente VANT) eram considerados puramente um instrumento para missões militares, mas agora eles têm se revelado verdadeiros aliados nos esforços de conservação do meio ambiente porque mostraram ser muito melhores para os estudos ecológicos do que o método tradicional de patrulha por terra.

Em junho/2015 o ICMBio (Instituto /chico Mendes) e a Univ. /federal de Goiás, realizaram um workshop em Brasília para discutir o uso de Drones na conservação da natureza.

Segundo o ICMBio (2015, p.1) "podemos usar os drones no cerrado, no monitoramento do fogo, ajudando as brigadas de incêndio, tanto antes como depois; podemos usar para a fiscalização de desmatamento, da caça predatória, da pesca indiscriminada, para o manejo e monitoramento da fauna e flora e plantas invasoras, com o intuito de prevenir ou realizar ações de minimização do dano".

Assim, como vantagens dos drones, destaca-se : são capazes de monitorar áreas fora do alcance dos seres humanos e tem uma visão absolutamente mais ampla do habitat dos animais ou das áreas de preservação, o que os tornam mais eficazes no envio de informações.

No comparativo com o método tradicional, os drones se mostraram-se mais precisos, pois a vista aérea dos aparelhos reduz a probabilidade, por exemplo, das aves serem perdidas pelo terreno ou obstáculos que bloqueiam a visão de quem patrulha em solo.

Isso abre novas possibilidades quando se trata de monitorar com mais precisão os ecossistemas da Terra.

Nos últimos anos, a tecnologia emergiu com força no campo da conservação do meio ambiente, e os seus impactos no terreno têm sido fundamentais e de longo alcance.

Eles têm ajudado a proteger espécies ameaçadas de extinção como os orangotangos e rinocerontes, acompanhando as atividades madeireiras e desmatamentos ilegais, e até mesmo o degelo no Ártico. 
Em se tratando do combate à caça furtiva, atualmente, já é possível utilizar sensores térmicos de onda longa nos drones, que detectam focos de calor emitidos no solo e identificam caçadores e acampamentos no período da noite, por exemplo.

Segundo Oliveira $(2.015$, p. principal), o potencial do uso dos drones na esfera ambiental é enorme".

Mas talvez um dos atributos mais interessantes do uso de drones na conservação é a possibilidade de se montar um mosaico das áreas prioritárias, o que permite aos pesquisadores monitorar mudanças no uso do solo, novos focos de desmatamento e plantações ou até mesmo princípios de incêndio. Os drones são os olhos que faltavam na luta pela preservação da natureza.

Uma das aplicações dos drones mais comemoradas, e já em ampla utilização, é o monitoramento ambiental. As aeronaves não tripuladas são alternativas mais baratas e eficientes para identificar áreas de desmatamento irregular, de queimadas, de controle de espécies ameaçadas de extinção, de proteção de mananciais, etc.

Elas conseguem voar em trechos não acessíveis a helicópteros, custam menos do que uma operação desse tipo feita com um veículo tripulado e fazem o mesmo serviço. A World Wildlife Fund (WWF), organização não governamental de proteção da natureza, tem utilizado os VANTS de baixo custo, equipados com câmeras, para monitorar populações animais em situação de risco em locais de difícil acesso ou de alta periculosidade, como os orangotangos de Sumatra, na Indonésia.

Os drones ganham a cada dia espaço também na agricultura e na pecuária. Sua versatilidade vale o investimento, já que podem desempenhar diversas funções com um custo relativamente baixo, variado de acordo com modelo e tecnologias embarcadas.

Nesse cenário, os VANTs podem ser utilizados para analisar a plantação e detectar pragas e doenças, falhas de plantio, excesso de irrigação, entre outros. São aliados a softwares para análise das imagens captadas. Do alto, é possível analisar a coloração da planta para detectar a presença de fungos, por exemplo.

O drone é ideal para proporcionar uma visão do alto de forma fácil e ágil e o seu sobrevoo oferece uma visão ampla de lugares distantes e de difíceis acessos.

Logo, com essas pequenas máquinas é possível ir a lugares onde estejam ocorrendo desmatamentos e, com localização precisa, combatê-los, bem como identificar áreas vulneráveis em fronteiras, onde são comuns a ocorrência de crimes ambientais transfonteiriços. 
Outra contribuição do drone para o meio ambiente trata-se do combate a incêndios, pois a proximidade do fogo é bastante perigosa e difícil para humanos. Por isso os drones conseguem sobrevoar incêndios para descobrir os focos do fogo e, consequentemente, controlálos. A tecnologia foi usada para este fim no incêndio do Porto de Santos, na cidade de Santos/SP, em abril de 2015.

\section{CRIME AMBIENTAL}

Crime é uma violação ao direito. Assim, será um crime ambiental todo e qualquer dano ou prejuízo causado aos elementos que compõem o ambiente: flora, fauna, recursos naturais e o patrimônio cultural.

Por violar direito protegido, todo crime é passível de sanção (penalização), que é regulado por lei.

Os crimes contra o meio ambiente estão tipificados na Lei n. 9.605/98. A legislação visa inibir condutas que atentem contra o meio ambiente :

Art. 29. Matar, perseguir, caçar, apanhar, utilizar espécimes da fauna silvestre, nativos ou em rota migratória, sem a devida permissão, licença ou autorização da autoridade competente, ou em desacordo com a obtida:

Pena - detenção de seis meses a um ano, e multa.

$\S 1^{\circ}$ Incorre nas mesmas penas:

I - quem impede a procriação da fauna, sem licença, autorização ou em desacordo com a obtida;

II - quem modifica, danifica ou destrói ninho, abrigo ou criadouro natural;

III - quem vende, expõe à venda, exporta ou adquire, guarda, tem em cativeiro ou depósito, utiliza ou transporta ovos, larvas ou espécimes da fauna silvestre, nativa ou em rota migratória, bem como produtos e objetos dela oriundos, provenientes de criadouros não autorizados ou sem a devida permissão, licença ou autorização da autoridade competente.

$\S 2^{\circ}$ No caso de guarda doméstica de espécie silvestre não considerada ameaçada de extinção, pode o juiz, considerando as circunstâncias, deixar de aplicar a pena.

$\S 3^{\circ}$ São espécimes da fauna silvestre todos aqueles pertencentes às espécies nativas, migratórias e quaisquer outras, aquáticas ou terrestres, que tenham todo ou parte de seu ciclo de vida ocorrendo dentro dos limites do território brasileiro, ou águas jurisdicionais brasileiras.

Todas essas condutas tipificadas, se realizadas, ensejam a cominação penal. Entretanto, em algumas áreas distantes e isoladas o agente pratica o crime e acaba ficando 
impune; uma vez que o Poder Publico não tem condições de fiscalizar adequadamente essas áreas. Como exemplo, destaca-se a floresta amazônica que é imensa em sua extensão e densidade, o que dificulta a fiscalização.

Nesse sentido, é que se verifica a possibilidade d o Drone chegar a esses locais, identificar o criminoso sem que ele mesmo saiba e enviar dados ao poder Público que poderá agir em tempo real para inibir e punir a conduta criminosa; uma vez que o bem ambiental é um bem fundamental à existência humana e, como tal, deve ser assegurado e protegido para uso de todos, conforme estatui o caput do artigo 225 da Constituição Federal.

O ambiente é protegido pela Lei n. ${ }^{\circ} 9.605$ de 12 de fevereiro de 1998 (Lei de Crimes Ambientais), que determina as sanções penais e administrativas derivadas de condutas e atividades lesivas ao meio ambiente.

A escala e intensidade com que esses crimes ocorrem demandam utilização de instrumentos que sejam capazes de dar respostas rápidas às situações emergenciais que frequentemente surgem nesses cenários.

Dados de satélites ou de sensores remotos aerotransportados são uma alternativa viável para o planejamento de operações de combate a tais atividades ilegais. Entre as principais vantagens em se utilizar esses dados está a cobertura global e repetitiva que permite o recobrimento de áreas de difícil acesso e de elevado grau de periculosidade para a vida humana.

Por outro lado, a utilização desses dados é limitada, no caso dos sensores orbitais, às datas programadas de passagens do satélite, o que ocasiona quase sempre uma defasagem temporal em relação à data de ocorrência dos fatos. No caso dos sensores aerotransportados, além da logística necessária à realização dos voos, o principal fator limitante está no alto custo dos sobrevoos para obtenção dos dados, além do risco à vida do piloto, dependendo da localização geográfica ou das condições meteorológicas da área onde a atividade ilegal é investigada.

Além dos fatores mencionados, em ambos os casos, é frequentemente demandada a utilização de imagens de alta resolução espacial (elevado nível de detalhamento), o que onera ainda mais as operações de aquisição de dados de sensores remotos.

Como resposta a esses desafios os veículos aéreos não tripulados (VANT’s) estão se consolidando como a mais nova tendência em sensoriamento remoto.

Além do menor custo de aquisição de dados quando comparados às plataformas tradicionais, as aeronaves não tripuladas trazem a possibilidade de monitoramento de atividades 
ilícitas em tempo real, o que torna esse instrumento uma excelente alternativa para a área de segurança e abre novas perspectivas para o monitoramento de ilícitos ambientais.

\section{OS DRONES E A PROTEÇÃO AMBIENTAL NA AMAZÔNIA}

Em uma região de dimensões continentais como a Amazônia, a identificação e o monitoramento de atividades irregulares de diversas naturezas se constituem num crescente desafio para as instituições governamentais em suas diferentes esferas de atuação.

Em algumas delas, como no Centro Gestor e Operacional do Sistema de Proteção da Amazônia (Censipam) do Ministério da Defesa, por exemplo, algumas dessas atividades estão relacionadas à geração de dados, em tempo hábil, que deem suporte a instituições com atribuições legais de combate e fiscalização a crimes ambientais na Amazônia, tais como o desmatamento na forma de corte seletivo ou corte raso, mineração ilegal, campos de pouso ilegais, entre outros.

A Amazônia, propriamente dita, estende-se por oito países do norte da América do Sul que formam o Pan Amazônia : Bolívia, Brasil, Colômbia, Equador, Suriname, Guiana, Peru, Venezuela), sendo que $60 \%$ da floresta amazônica encontra-se no Brasil

Segundo Moura (2011, p.13) o conceito de Amazônia Brasileira, "que compreende uma área de 3,7 milhões de Km2, é substituído no Brasil por Amazônia Legal, um conceito essencialmente político, que aumenta em 1,3 milhões de Km2 a área da Amazônia Brasileira”.

E continua Moura (2011, p. 13): “a Amazônia Legal faz fronteira com sete países da América do Sul, totalizando $11.728 \mathrm{~km}$ de fronteira terrestre e $1.820 \mathrm{~km}$ de fronteira marítima com o oceano Atlântico e abrange os estados do Amazonas, Amapá, Acre, Mato Grosso, Maranhão (a parte oeste do meridiano de $44^{\circ}$ de longitude oeste), Pará, Rondônia, Roraima e Tocantins".

Os atrativos dessa região provocaram, ao longo do tempo, um aumento dos crimes ambientais e outras atividades ilegais em larga escala, associados à exploração predatória dos recursos naturais e impulsionados por vários fatores, tais como a abertura de estradas pioneiras, o crescimento das cidades, a ampliação de pecuária extensiva, a acelerada exploração madeireira e a crescente agricultura intensiva de monoculturas (Ferreira, et al. 2005), além da exploração mineral desordenada.

Entre algumas das principais atividades ilegais decorrentes desses fatores estão o desmatamento ilegal na forma de corte seletivo ou corte raso, que na maioria das vezes é 
precedido por diversas outras práticas ilegais, como a construção de pistas de pouso clandestinas para escoamento de produtos e exploração ilegal de garimpos.

Nesse cenário, o uso de dados de sensoriamento remoto provenientes de veículos aéreos não tripulados, integrados com dados de satélites é a alternativa mais eficiente de monitoramento para a região Amazônica.

Ainda assim, são poucas as iniciativas concretas de monitoramento com o uso de veículos aéreos não tripulados.

A maior parte dos projetos ainda está em fase de testes ou de prospecção para aquisição de VANT's, sobretudo porque a legislação que regula essa atividade ainda está em fase de discussão e porque são necessárias autorizações específicas para as operações, o que dificulta a logística das atividades.

Algumas das principais iniciativas para uso de VANTs no monitoramento da Amazônia, estão relacionadas a aplicações voltadas ao combate das atividades irregulares, como descrito a seguir.

Segundo Moura (2011, p.79), “o corte seletivo caracteriza-se como uma atividade ilegal característica da região amazônica. É o início do processo de desmatamento e está relacionado à atividade de exploração madeireira que ocasiona a degradação florestal progressiva".

A primeira etapa compreende a retirada das madeiras mais nobres, depois as madeiras para a construção civil e, por fim, são colhidas as árvores de madeiras leves remanescentes, para a produção de compensados e placas.

Posteriormente, as árvores de menor porte são derrubadas e toda a vegetação rasteira é destruída. Sobram poucas árvores frondosas que são protegidas, como é o caso da castanheira, ou que não têm valor comercial, como as palmeiras, o que dificulta o processo de detecção por meio de imagens de sensores remotos.

O empobrecimento "oculto", resultante da exploração madeireira, também provoca indiretamente o corte raso das florestas nas regiões de fronteira. Isso ocorre porque grande parte das estradas clandestinas, construídas para a extração e o escoamento da madeira no coração da floresta amazônica, torna-se novos eixos de exploração.

Para esses casos, imagens de alta resolução espacial são as mais adequadas por possibilitarem a detecção dos pátios e estradas maiores, além de feições mais finas da exploração - estradas menores (ramais de arraste) e clareiras simples e múltiplas 
A presença de estradas e pátios de estocagem nas imagens é o principal indicador da ocorrência de exploração madeireira.

A detecção dessas feições pode ser útil não só para localizar a atividade nas imagens, mas também a forma como ela foi conduzida.

O principal trabalho prático e operacional decorrente da utilização de imagens de sensores remotos para identificação de corte seletivo é a fiscalização dos planos de manejo florestal que compreende um conjunto de técnicas empregadas para a colheita criteriosa de parte das árvores maiores, de tal maneira que as menores sejam protegidas para colheitas futuras.

Os planos de manejo, segundo Oliveira (2013, p. 226) "são licenças que permitem a extração de madeira apenas de áreas previamente determinadas durante um determinado intervalo de tempo".

Assim, por meio de imagens de sensores remotos, é possível fiscalizar os planos de manejo autorizados avaliando se houve exploração no período autorizado; se a exploração ultrapassou os limites estabelecidos; se houve exploração antes da aprovação do plano de manejo, entre outros.

Os resultados dessas análises dão suporte para apuração de possíveis irregularidades decorrentes das licenças.

O uso de VANT's para essa finalidade tem sido testado pelo Serviço Florestal Brasileiro (SFB). Segundo o SFB (2016, p. principal) :

Para essa finalidade, é possível verificar a quantidade de madeira retirada nas áreas concedidas com o uso de VANT's. Isso permite agilidade no sistema de rastreamento da madeira legal, já que é possível reduzir significativamente o custo representado pela ida da equipe técnica ao campo. Conforme apontamentos do SFB, o concessionário é obrigado a informar toda a produção no sistema de fiscalização e os técnicos vão a campo checar a informação.

E continua o SFB (2016, p. principal) :

Como exemplo, os testes com três VANT's permitiram quantificar 25 mil metros cúbicos de madeira, que correspondem a cerca de 700 carretas, num prazo de 6 horas. Se essa quantidade fosse medida por técnicos em campo, seriam necessários 15 dias para a averiguação. Dessa forma, o sistema de rastreabilidade pode permitir que a madeira adquirida da concessão seja monitorada ao longo de toda a cadeia de produção, de maneira que o consumidor que adquirir uma madeira cerrada proveniente de área de concessão ou o importador da Europa ou dos Estados Unidos vai poder, por meio de um aplicativo de celular, saber exatamente a área, a árvore e a coordenada geográfica que originaram o produto que ele está adquirindo. 
Outra atividade irregular que caracteriza o estágio seguinte ao corte seletivo é o corte raso. É o estágio extremo do desmatamento, em que o padrão observado representa a retirada completa da vegetação original num intervalo temporal curto.

Nesse caso, a principal vantagem do uso do VANT está na velocidade de obtenção de informações para suporte à tomada de decisão pelos órgãos com atribuições legais de combate ao desmatamento.

Outra atividade ilegal de grande impacto é o garimpo ilegal. Há uma quantidade imensa de ocorrências minerais distribuídas em todos os estados da Amazônia. Muitas dessas substâncias minerais estão localizadas em áreas protegidas, ou seja, unidades de conservação (UC) e terras indígenas (TI).

Entretanto, a extração dos recursos minerais nessas áreas requer autorização condicionada a normas específicas.

Assim sendo, o Poder Público não autoriza a pesquisa mineral e, consequentemente, a extração de bens minerais em áreas de proteção integral.

Nas áreas de conservação de uso sustentável, é consultado o órgão ambiental competente sobre a conveniência ou não dos trabalhos de pesquisa e/ ou extração mineral, cabendo, quando for o caso, a apresentação do licenciamento ambiental para o prosseguimento dos trabalhos.

Como na maior parte das áreas, mesmo naquelas não consideradas como protegidas, é frequente a exploração mineral à revelia dos procedimentos legais, a maior parte das explorações constitui-se em atos ilícitos.

No Brasil, muitos garimpos quase sempre estão associados a confrontos, assassinatos, roubos, disputas de terra, prostituição, vícios, insegurança, impunidade, patrocínio de armas e narcotráfico e à degradação ambiental.

Isso porque os garimpos ilegais são extremamente difíceis de serem controlados. Situam-se em regiões de difícil acesso, são dispersos pelo país, são migratórios e não há regularidade na mão de obra e no regime de trabalho.

Os muitos riscos para se estudar diretamente essa atividade faz do sensoriamento remoto a principal ferramenta de monitoramento de atividades ilícitas ligadas a extração mineral.

Segundo Antunes (2005, p. 87), "um dos grandes desafios para um monitoramento efetivo das áreas de mineração é a identificação do processo no seu estágio inicial”. 
Como não há um padrão espacial definido associado a essas áreas, a indicação de áreas de extração mineral em imagens de média resolução espacial depende da habilidade do analista em fazer uma análise contextual da área investigada.

Por outro lado, em imagens de alta resolução espacial essas áreas são facilmente identificadas pela facilidade de visualização da extensão do impacto.

Nesse sentido, o uso de um VANT permitiria, em pequeno intervalo de tempo, o mapeamento de todas as áreas de mineração em áreas críticas de ocorrência desse tipo de ilícito, como as terras indígenas, por exemplo.

Essas áreas, de grande importância pelos aspectos étnicos e para conservação da biodiversidade, são de difícil acesso, fortemente impactadas por essa atividade e onde as ações governamentais se restringem a algumas instituições pelas especificidades da legislação brasileira para essas áreas.

Iniciativas mais concretas têm sido conduzidas pela Secretaria de Estado de Indústria, Comércio e Mineração (Seicom) do estado do Pará, que adquiriu um VANT com a finalidade inicial de intensificar a fiscalização mineral no estado.

Segundo a SEICON (2015, p. principal), “o investimento na compra do VANT foi de cerca de $\mathrm{R} \$ 300$ mil aproximadamente, e a perspectiva, pela potência, alcance e função do equipamento, é que esse investimento represente economia de no mínimo R\$ 1,5 milhão para o estado".

O drone tem câmeras de alta definição que também captam imagens em infravermelho e serve para mapear as atividades das minas.

As imagens em alta resolução captadas permitirão a realização de um cálculo volumétrico que indicará a quantidade exata do que está sendo retirado das minas mensalmente, além de quantificar o volume estocado e identificar os tipos de minérios.

Além disso, o equipamento pode ser operado em grandes distâncias $(30 \mathrm{~km})$, a altitudes de até 3.000 metros, além de voar por um período de até cinco horas e meia, viabilizando a fiscalização em áreas de difícil acesso ou ainda onde possa ser colocada em risco a integridade física da equipe de fiscalização.

Outra vantagem é que o equipamento é capaz de cobrir uma extensa área em um único voo, permitindo a perfeita identificação de objetos com dimensão superior a $43 \mathrm{~mm}$ (milímetros).

Como suporte a todas as atividades irregulares descritas, as pistas não homologadas aparecem como elementos de fundamental importância para a compreensão de como se 
configura espacialmente uma determinada atividade ilegal, pelo fato de que fazem parte da logística de várias atividades ilícitas.

Para identificação e monitoramento de pistas clandestinas, por exemplo, as imagens de radar são uma excelente alternativa, sobretudo na Amazônia, em razão da cobertura de nuvens e pelo fato de que essas imagens favorecem as diferenças texturais e geométricas dos alvos imageados, facilitando a identificação das pistas, principalmente em áreas de floresta.

$\mathrm{Na}$ ausência de dados de radar, a identificação das pistas depende da disponibilidade de imagens de alta resolução espacial ou de dados que validem as feições de pistas identificadas em imagens de média resolução, como as do satélite CBERS.

O uso de um VANT pode melhorar substancialmente a capacidade de análise dessa atividade. O uso integrado dos sensores EO/IR e radar a bordo do VANT dispensaria validação da informação no campo, propiciando a tomada rápida de decisão sobre a ação a ser executada.

Em operação integrada da Força Aérea Brasileira na fronteira Brasil-Colômbia, por exemplo, o uso do sensor EO/IR do VANT Hermes 450 da FAB possibilitou a identificação de pistas de pouso clandestinas.

A confirmação da existência de uma pista de 1,5 mil metros de comprimento e 15 de largura, própria para pequenas aeronaves, propiciou rápida tomada de decisão que resultou na destruição da pista.

\section{CONCLUSÃO}

Em virtude do capitalismo desenfreado, os crimes contra a natureza avançam a cada dia. É preciso encontrar mecanismos mais eficazes para combater e reprimir essas ações. A possibilidade de eliminar essas ações na origem, tendo maior eficácia, passou a existir com a chegada dos VANTs, ou os popularmente chamados de drones

A tecnologia de VANT's é recente e a possibilidade de utilizá-los a favor do meio ambiente representa um grande avanço para o monitoramento de atividades ilícitas na Amazônia.

Os drones, por serem equipamentos e sem piloto, podendo ser monitorados a distância, auxiliam muito, pois podem chegar a lugares que o homem, em sistema convencional não chegaria ou demoraria muito mais tempo para lá chegar. Dessa forma, ele agiliza ações e, como é um compactador inteligente, tira fotos, e mapeioa o ambiente, facilitando o trabalho e obtendo melhor resultado, pois tem amior precisão; podendo assim, auxiliar nas inspeções ambientais, prevenindo danos futuros e alertando sobre os danos presentes. 
Para o Censipam e todas as instituições parceiras que operam na região amazônica, a disponibilidade de plataformas alternativas de aquisição de imagens traz perspectivas de um monitoramento mais efetivo e da geração sistemática e operacional de dados consistentes e atualizados, os quais podem ser disponibilizados e compartilhados com maior frequência.

Mais especificamente, a operação simultânea de sensores a bordo de VANT's possibilitará a definição de padrões espaciais associados às atividades dos responsáveis por diversos crimes ambientais em imagens de diferentes fontes, principalmente de sensores radar, que são os mais adequados para a Amazônia.

O menor custo operacional do VANT em relação aos sensores aerotransportados viabiliza maior frequência de obtenção de dados e a geração de uma biblioteca espectral de alvos.

\section{REFERÊNCIAS}

BRASIL. Lei $n^{\circ}$ 6.938/81 - Politica Nacional do Meio Ambiente. Congresso Nacional. Brasília: 1981

BRASIL. Constituição da República Federativa do. Congresso Nacional, Brasília, 1988.

BRASIL. Lei nº 9.605/98 - Lei de Crimes Ambientais. Congresso Nacional : Brasília, 1998.

BRASIL. Instrução Suplementar no 21/002 - ANAC - Agencia nacional de Aviação Civil.

EPC - Empresa pelo Clima. Uso de drones no monitoramento da Amazônia. Disponível em:http://empresaspeloclima.com.br/uso-de-drones-no-monitoramento-daamazonia?locale=pt-br, consultada em 24 set 2016.

ICMBio. Drones Aliados a proteção Ambiental. Disponivel em http://www.ecobrasilia.com.br/2015/08/06/drones.aliados.na.proteção.ambiental/ consulta em 23 set 2016. 2011.

MOURA, Luiz Antônio Abdalla de. Economia Ambiental. Belo horizonte : Del Rey,

OLIVEIRA, Raul M. Freitas de. Concessão Florestal. São Paulo : Jhmizuno, 2.013. 